\title{
Analysis
}

\section{The Thrive Model of adolescent health care}

\section{BACKGROUND}

Many health outcome indicators of the UK population are deteriorating and compare unfavourably with less prosperous OECD countries. The adolescent population, comprising 1 in 5 of the UK population, ${ }^{1}$ is no different, with comparatively poor health indicators relating to physical, sexual, and mental health. The rapid physical and psychosocial changes that occur in adolescence, which influence the health behaviours we see and which many health professionals feel ill equipped to meet, contribute to this.

A study from the Nuffield Trust and Association for Young People's Health in $2019^{2}$ highlighted UK death rates from asthma in the 10-24-year age group as being the highest across all 14 European comparator nations, with obesity rates in UK 15-19-year-olds ranking highest too. Similarly, a 2013 UNICEF report concluded that young people in the UK have the poorest levels of sexual health and wellbeing compared with other industrialised nations. ${ }^{3}$ This was echoed in an analysis of data from the latest British Survey of Sexual Attitudes and Lifestyles (Natsal-3), ${ }^{4}$ which concluded that a substantial proportion of young people in Great Britain were becoming sexually active under circumstances incompatible with positive sexual health. Furthermore, $75 \%$ of mental health problems begin below the age of 24 years ${ }^{5}$ and there is a growing body of evidence demonstrating the everincreasing number of mental health issues that this age group faces. This led NHS England Chief Executive Simon Stevens to state at the NHS Confederation in June 2018 that the UK's children were being hit by a 'double epidemic' of mental illness and obesity.

Evidence also highlights that good health in adolescence leads to good health in adulthood and this is particularly so with emotional health. A report by Goodman et al in 2015 found that Emotional health at age 16 [is] a stronger predictor of mental health and life chances at age 30 than either demographic or socio-economic factors.' It has also been estimated that investment in this age group will yield a 10-fold economic benefit for later adulthood?

A review of data drawn from the Hertfordshire Health Related Behaviour Surveys relating to the health of young people supported these findings and included concerning levels of obesity, and similarly poor sexual and mental health indicators.

\section{AMBITION}

It is essential to develop a cost-effective model of health care to address these needs of UK youth. National surveys suggest that young people regularly access their GPs ${ }^{8,9}$ and this was supported by a local secondary school survey showing that $78.3 \%$ of pupils had seen their GP in the last year. This would suggest that primary care is the ideal context in which to deliver adolescent health care. However, the same data suggested that the experience of both young people and GPs was not always positive. A significant percentage of young people, in particular girls, reported feeling uneasy with their GPs. This was reflected in the school survey with comments such as feeling 'embarrassed', 'awkward', and 'judged'. To counter this, focus groups suggested that GPs should adopt an informal, non-judgemental approach with

\section{Box 1. The Thrive Model}

\section{Structure Process}

Weekly extended-access clinics

At a time identified in school surveys as most popular

Held in a central, accessible GP surgery

Clinics dedicated to 11-25-yearolds

Young-person friendly according to 'You're Welcome' criteria with welcoming environment and staff

Run by well-informed and well-
supported GPs

15-minute appointments

(Extended to 30 minutes in response to feedback) Well-resourced clinics through local partnerships (signposting material and information)

Good clinical governance and local partners to shape and deliver the YPC

Suitable publicity around the process
Quality improvement outcomes

Outcome measures:

- improved adolescent health through better experience and use of general practice; and

- well-informed and wellsupported GPs running the service

Delivery of comprehensive training Process measures based on workshops to participating GPs to 'You're Welcome' criteria: upskill in adolescent health care and knowledge of local services

Workshops include specific manage health, social, educational, • at ease with GP and psychological transition

Young person rings own surgery Balancing measures: to book YPC extended-access appointment

(Follow-up appointments now

- overall attendance figures; and

- type of presenting issue offered within the YPC in response

to feedback)

Staff training in the process of

booking young people in to the YPC

Holistic psychosocial health

template to be completed while waiting for the appointment

Quality improvement questionnaire

based on the 'You're Welcome'

criteria to be completed at the close of every consultation

Participating GPs to complete

regular feedback questionnaires

Continuous professional

development and ongoing support

for GPs through WhatsApp

support group and regular face-

to-face meetings

(Clear pathway developed for managing emotional distress in response to GP feedback J

ease of booking;

- ease of access;

- suitability of timing

- comfortable in environment; and \section{.}


use of first names and informal dress. Local GPs also echoed national reports of feeling ill equipped to manage this age group.

Therefore, the ideal setting in which to deliver adolescent health care seemed to be one embedded in primary care but with appropriate adjustments to make it more young person friendly and to provide better support for the local GPs.

Following review of the approaches tested within the GP Champions project in 2015, ${ }^{10}$ the Thrive Model of adolescent health care was developed. Embedding the model within the existing extended-access infrastructure, already funded and well established in general practice, overcame many of the challenges of accessing sustainable resources faced by these pilots. Further value was added by signposting or referring young people to a broad blend of services that were not fully utilised in the local area. Although no formal health economics evaluation was conducted, utilising existing services in this way contributed to the costeffectiveness of the model.

\section{THE THRIVE MODEL}

The Thrive Model was developed in collaboration with young people through school surveys, focus groups, and meetings with young commissioners and peer volunteers, taking into account local data from the Hertfordshire Health Related Behaviour Surveys and third-sector organisations.

The model (Box 1) was developed to incorporate the Department of Health and Social Care (DHSC) 'You're Welcome' standards for a young-person-friendly service, which broadly encompass eight domains: accessibility; publicity; confidentiality and consent; environment; staff training and attitudes; joined-up working; young people's involvement; and health issues and transition; with additional criteria relating to sexual and reproductive health and mental health. The model also incorporates the five core attributes of general practice as identified by the King's Fund report:11 person-centred, holistic care; accessibility; coordination; continuity; and community focus.

In April last year, following local partnership building and relevant training, a pilot young person's clinic (YPC) based on this Thrive Model was launched in the St Albans and Harpenden locality. YPCs are held every Thursday from 4-7 pm in an easily accessible location. Initially appointments lasted 15 minutes but, with the increasing burden of complex mental health issues presenting to the clinic, and in response to GP and patient feedback, these appointments were lengthened to 30 minutes. In addition, a clear pathway was developed, with embedded links for managing emotional distress in young people, to better support the GPs running the clinics. Following feedback on the booking process, the facility to arrange follow-up appointments in the clinic was introduced. The service is continuously fine tuned in response to such patient and GP feedback.

\section{REVIEW}

A review of the clinic data was carried out in October. The data clearly demonstrated that the clinic provided a safe environment where young people felt at ease talking to their GP about sensitive issues, including those related to sexual and mental health. Eightysix per cent of young people scored their clinic experience as $8 / 10$ or above, with $93 \%$ stating that their appointment suited them better than standard GP appointments. Comments on the feedback questionnaire such as 'felt more comfortable and at ease: 'more time to talk and find the best solution. 'felt listened to', 'didn't dismiss me', and 'specific to young people' confirmed that young people especially valued the GP approach and expertise. Data also confirmed that the clinic met the DHSC 'You're Welcome' criteria for a young person's service, and the high attendance rate further supported this.

Feedback from colleagues both within and outside the service suggested that they too felt well supported, with access to high-quality information around referral pathways and excellent resources from local partnerships. The increased time pressure and emotional burden resulting from the high percentage of vulnerable young people with mental health issues $171 \%$ of presentations) were partly offset by effective mobile phone support during clinic and through regular co-supervisions, and there are plans to engage other mental health services to support the clinic further.

\section{NEXT STEPS}

As extended-access and county-wide partnerships are already in place, and the training programme already established, the service can be cost-effectively upscaled with further value added through diversification of the skill-mix to include counsellors, adolescent social prescribers, and nurses in line with primary care transformation. Such a cost-effective, young-person-friendly model could play a crucial role in helping young people tackle the current UK health crisis.

\section{ADDRESS FOR CORRESPONDENCE}

\section{Alison Cowan}

Thrive Young Person's Service, St Albans and Harpenden GP Federation, 1 Hawkes Drive Redbourn, Hertfordshire AL3 7BL, UK.

\section{Email: alcowanadoctors.org.uk}

\section{Alison Cowan,}

GP Lead, Thrive Young Person's Service, St Albans and Harpenden GP Federation (part of Herts Valleys Clinical Commissioning Group), Redbourn.

\section{Provenance}

Freely submitted; externally peer reviewed.

DOI: https://doi.org/10.3399/bjgp20X713345

\section{REFERENCES}

1. Hagell A, Shah R. Key data on young people 2019. London: Association for Young People's Health, 2019.

2. Shah R, Hagell A, Cheung R. International comparisons of health and wellbeing in adolescence and early adulthood. Research report. London: Nuffield Trust, Association for Young People's Health, 2019.

3. UNICEF Office of Research. Child well-being in rich countries: a comparative overview. Innocenti Report Card 11. Florence: UNICEF, 2013.

4. Palmer MJ, Clarke L, Ploubidis GB, Wellings $K$. Prevalence and correlates of 'sexual competence' at first heterosexual intercourse among young people in Britain. BMJ Sex Reprod Health 2019; 45(2): 127-137.

5. Kessler RC, Berglund P, Demler O, et al. Lifetime prevalence and age-of-onset distributions of DSM-IV disorders in the National Comorbidity Survey Replication. Arch Gen Psychiatry 2005; 62(6): 593-602.

6. Goodman A, Joshi H, Nasim B, Tyler C. Social and emotional skills in childhood and their longterm effects on adult life: a review for the Early Intervention Foundation. London: UCL Institute of Education, 2015.

7. Shehan P, Sweeny K, Rasmussen B, et al. Building the foundations for sustainable development: a case for global investment in the capabilities of adolescents. Lancet 2017; 390(10104): 1792-1806.

8. Balding A, Regis D. Young people into 2018. Exeter: Schools Health Education Unit, 2018.

9. Brooks R, Magnusson J, Klemera E, et al. Health behaviour in school-aged children. English national report 2014. Hatfield: University of Hertfordshire, 2015.

10. Partnership between the Association for Young People's Health (AYPH), the Royal College of General Practitioners' (RCGP) Adolescent Health Group, and Youth Access. GP Champions for Youth health project: commissioning effective primary care services for young people. London: Association for Young People's Health, 2015.

11. Baird B, Reeve H, Ross S, et al. Innovative models of general practice. 2018. https://www. kingsfund.org.uk/publications/innovativemodels-general-practice laccessed 7 Oct 2020). 